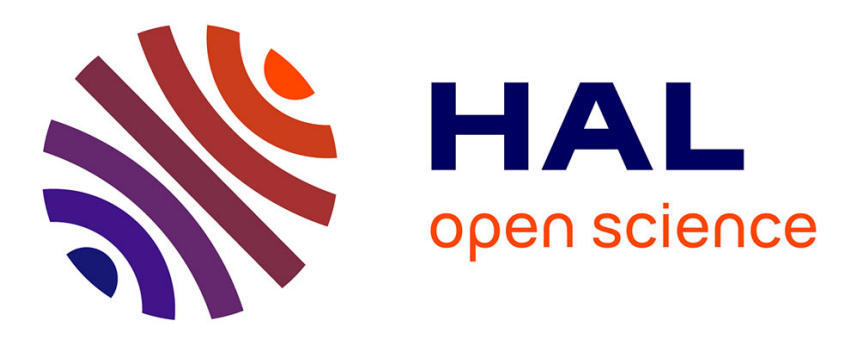

\title{
Isoform-specific differences in the nitrite reductase activity of nitric oxide synthases under hypoxia
}

Ivan Mikula, Suzanne Durocher, Pavel Martasek, Bulent Mutus, Anny Slama-Schwok

\section{- To cite this version:}

Ivan Mikula, Suzanne Durocher, Pavel Martasek, Bulent Mutus, Anny Slama-Schwok. Isoform-specific differences in the nitrite reductase activity of nitric oxide synthases under hypoxia. Biochemical Journal, 2009, 418 (3), pp.673-682. 10.1042/BJ20080987 . hal-00479026

\section{HAL Id: hal-00479026 https://hal.science/hal-00479026}

Submitted on 30 Apr 2010

HAL is a multi-disciplinary open access archive for the deposit and dissemination of scientific research documents, whether they are published or not. The documents may come from teaching and research institutions in France or abroad, or from public or private research centers.
L'archive ouverte pluridisciplinaire HAL, est destinée au dépôt et à la diffusion de documents scientifiques de niveau recherche, publiés ou non, émanant des établissements d'enseignement et de recherche français ou étrangers, des laboratoires publics ou privés. 


\section{Isoform-specific differences in the nitrite reductase activity}

\section{of nitric oxide synthases under hypoxia}

\section{Ivan Mikula ${ }^{2,3 \$}$, Suzanne Durocher ${ }^{3 \$}$, Pavel Martasek ${ }^{2}$, Bulent Mutus ${ }^{3}$, and Anny Slama-Schwok ${ }^{1,2^{*}}$}

\footnotetext{
${ }^{1}$ Virology et Immunologie Moleculaires, INRA UR892, Domaine de Vilvert, 78350 Jouy en Josas, France

2 Laboratory for Optics and Biosciences, INSERM U696, CNRS UMR7645, Ecole Polytechnique, 91128 Palaiseau, France;

${ }^{2}$ Dept of Pediatrics and Center for Genomics, First School of Medicine, Charles University of Prague, the Czech Republic;

${ }^{3}$ Department of Chemistry \& Biochemistry University of Windsor, Windsor Ontario, Canada,
}

${ }^{\$}$ Both authors IM and SD contributed equally

CORRESPONDING AUTHOR: Anny Slama-Schwok, PhD

Email: Anny.Schwok@jouy.inra.fr, tel.: 331346526 04, fax: 33134652621 


\begin{abstract}
Nitrite $\left(\mathrm{NO}_{2}{ }^{-}\right)$recycling to nitric oxide (NO) is catalyzed by a number of enzymes and induces a protective vasodilatory effect under hypoxia/ ischemia. In the present work, we tested the in vitro ability of the three NOS isoforms to release NO from nitrite under anoxia using electrochemical detection, chemiluminescence and absorption spectroscopy. The release of free NO from anoxic nitrite solutions at $15 \mu \mathrm{M}$ was specific to the endothelial isoform eNOS and did not occur with neuronal nNOS and inducible iNOS. Unlike xanthine oxidase, eNOS reductase domain did not recycle nitrite to NO and WT eNOS did not reduce nitrate. Our data suggest that structural - and by inferencedynamic differences between nNOS and eNOS in the distal heme domains account for eNOS being the only isoform capable of converting nitrite to $\mathrm{NO}$ at $\mathrm{pH}=7.6$.

In human dermal microvascular endothelial cells under careful control of oxygen tension, the rates of NO formation determined by chemiluminescence were enhanced $\sim 3$.6-fold and $\sim 8$.3-fold under hypoxia (2ppm $\mathrm{O}_{2}$ ) and anoxia (argon) respectively compared to normoxia ( 22ppm $\mathrm{O}_{2}$ ) using $10 \mu \mathrm{M}$ extracellular nitrite. NOS inhibitors inhibited this hypoxic NO release. Our data show that eNOS is unique in that it releases NO under all oxygen levels from normoxia to complete anoxia at physiological $\mu \mathrm{M}$ nitrite concentrations. The magnitude of the hypoxic NO release by the endothelial cells suggest that the endothelium could provide an appropriate response to acute episodic ischemia and may explain the observed eNOS-expression specific protective effect as a short-term response in animal models of acute hypoxia.
\end{abstract}

Running title: Hypoxic nitrite reduction by eNOS

KEYWORDS: NO-synthase, microvascular endothelial cells, Nitrite reduction, Hypoxia, NO, NO electrode, chemiluminescence 
Recent findings have greatly boosted interest in the role of nitrite anion $\left(\mathrm{NO}_{2}{ }^{-}\right)$in the regulation of vascular tone [1-5] since nitrite can elicit some of the same physiological responses as nitric oxide (NO) in cell signaling and in the modulation of gene expression [6]. In addition, nitrite has been shown to have protective, hypoxic buffer effects, under conditions of low oxygen tension [7-9]. Significant quantities of nitrite are available in the tissues and the circulatory system of mammals. For example, typical nitrite levels in plasma range from $0.1 \mu \mathrm{M}$ to $1.0 \mu \mathrm{M}$ and in normoxic tissues from $0.5 \mu \mathrm{M}$ to $2 \mu \mathrm{M}$, with still higher levels of up to $20 \mu \mathrm{M}$ being reported in vascular tissue of rats $[3,5]$.

Although the beneficial effects of nitrite under low oxygen tension were attributed to the reduction of nitrite back to NO, the dominant reaction pathway in vivo is still debated. Direct uncatalyzed oneelectron reduction is very slow at physiological $\mathrm{pH}$ in tissues [10], but takes place under exceptionally acidic conditions as in acidosis (below $\mathrm{pH}=6.5$ ), in hypoxic tumor [11] or in the stomach $(\mathrm{pH} \approx 2.0$ ) [12]. Certain mammalian enzymes and proteins including xanthine oxido-reductase (XOR) [9, 13], deoxy-hemoglobin [4, 7-8, 14-15], mitochondrial cytochrome $C$ oxidase [16] and cytochrome P450 [17] display nitrite reductase activity supplementary to their normal physiological function. Currently, it remains unclear whether nitrite is transformed into free NO in the biological milieu or involve transient species as S-nitrosation of thiols on the protein as reported in deoxy-hemoglobin $[4,17]$. It is thus conceivable that a dynamic equilibrium between nitrite and nitrosothiols could be established and mediated by several proteins under hypoxia. Moreover, the above proteins possess different $\mathrm{K}_{\mathrm{M}}$ for oxygen. Therefore, various nitrite reduction pathways are triggered by different local oxygen concentrations and, thus may not occur simultaneously or competitively.

Clinical studies have implicated the NO-synthases as participants in the early or preconditioned response to hypoxia [18-22]. The three NOS isoforms modulate this response differently. The endothelial isoform (eNOS) was found to be protective in brain ischemia and stroke, in contrast to the neuronal isoform nNOS [18-19, 22-24]. In the heart, the inducible isoform was found to be cardioprotective by myocardial preconditioning [20]. These effects have been independently confirmed with the use of knock-out (KO) animals. Studies in mice with eNOS-KO have shown exacerbation of injury with increased infarct size. Conversely, studies conducted with transgenic mice showed that nNOS-KO resulted in decreased infarct size in models of focal cerebral ischemia [18-19, 22]. These data suggest that the NOS isoforms do not react similarly under ischemia or acute hypoxia.

The NOS enzymes catalyze the synthesis of NO from L-arginine via an oxygen consuming pathway [25]. Large quantities of eNOS are available throughout the vasculature since this isoform is expressed in the endothelial cells which align the inside surface of all blood vessels. The arginine pathway is ineffective under conditions of low oxygen tension, (i.e. $<4-10 \mu \mathrm{M}$ ) since the reported $\mathrm{K}_{\mathrm{M}}$ for oxygen of eNOS, iNOS and nNOS are 4-10 $\mu \mathrm{M}, 130 \mu \mathrm{M}$ and $350 \mu \mathrm{M}$ respectively [25]. However, we have shown that in vitro, eNOS is not deactivated when starved of oxygen but rather starts to reduce nitrite to NO [26]. In a subsequent study with cultured endothelial cells (bEND3), we observed that the absence of oxygen enhanced rather than a suppressed the NO released from cells [27]. Since eNOS is the only isoform expressed by bEND3 cells [28], these experiments suggested that intracellular eNOS reduced nitrite to NO under acute anoxia, although nitrite would not penetrate these cultured cells in the timescale of the experiments [26-27].

In the current paper, we compare the ability of the three NOS isoforms to act as nitrite reductases under anoxia. We also investigate the role of the heme domains in each of the isozymes in the nitrite reduction since the hemoproteins hemoglobin and cytochrome $\mathrm{C}$ oxidase are also known to act as nitrite reductases under hypoxia. Since the three NOS isoforms share high homology, we can adequately test requirements of a heme and/or flavins for nitrite reduction. Additionally, we compare the effect of anoxia at physiological $(15 \mu \mathrm{M})$ and supra-physiological $(500 \mu \mathrm{M})$ nitrite concentrations or $10 \mu \mathrm{M}$ nitrate. Cellular studies using HDMEC were also performed under strict control of oxygen tension to independently test for $\mathrm{NO}$ formation under conditions where the aerobic L-Arginine pathway of eNOS is turned off i.e. at $\left[\mathrm{O}_{2}\right]$ below the $\mathrm{K}_{\mathrm{M}}$ for oxygen. The hypoxic NO formed by these cells was largely enhanced by ca 3.6 folds compared to normoxic conditions, whereas complete anoxia further enhanced this release to 8.3 fold. NO release was inhibited by L-NMA (L-N-MethylArginine), but not the 3-Bromo-7-nitroindazole, a nNOS specific inhibitor. Both in vitro and cellular data confirm that the only NOS isoform with a nitrite reductase activity is eNOS, with relevance for an "emergency" NO release near the endothelium in acute hypoxia. 


\section{Experimental}

Chemicals: L-Arginine, $\beta$-NADPH (99.8\% purity), 6R-5,6,7,8-tetrahydrobiopterin $\mathrm{BH}_{4}$ and calmodulin, sodium nitrite, ferrous sulfate, sodium-diethyldithiocarbamate (DETC) and Tris base were purchased from Sigma (St Quentin, France). The isothiourea derivatives SEITU (s-ethyl-isothiourea) IPITU (isopropyl-isothiourea) and NOHA (N-hydroxyarginine) were purchased from Alexis Biochemicals (Coger, France). The certified dilutions of NO gas in argon at concentrations of $1 \%$ and $0.1 \%$ were purchased at Alphagaz (Paris, France). High purity argon (99.9995\%) from Air Products (Paris, France) was used in all experiments. The cDNA constructs for expression of nNOS and iNOS were kindly provided by Dr. L.J. Roman (laboratory of Prof. Bettie Sue Masters, UTHSC at San Antonio, TX, USA). Recombinant eNOS, iNOS and nNOS holoenzymes were prepared as described previously and their activity were tested by the hemoglobin capture assay as described [29-30]. The absorption spectra, peaking at 395-397 nm attested that the proteins were active in high spin ferric forms in the presence of L-arginine and $\mathrm{BH}_{4}$ before the experiments. Argon (high purity 5.0) and $2 \mathrm{ppm} \mathrm{O}_{2}$ (corresponding to $6 \mu \mathrm{M}$ oxygen) plus argon (high purity 5.0) were purchased from Praxair (Canada, Mississauga ON).

Methods:

Preparation of the samples: The nitrite solutions containing arginine (and $\mathrm{BH}_{4}$, calcium, calmodulin as specified) in $50 \mathrm{mM}$ Tris buffer at $\mathrm{pH}=7.6$ with or without protein were carefully degassed by repetitive cycles of vacuum and argon purging in small vials sealed with a rubber stopcock and kept on an ice bath. The degassed solutions were then transferred in the optical cell with a gas-tight Hamilton syringe. The optical quartz cuvette was sealed by a teflon stopper with three holes to allow insertion of an ISO-NOP200 NO - electrode (WPI ltd, Aston, UK), a continuous argon inflow through a stainless steel needle and a teflon capillary tube for injection of reductant or outflow of exhaust argon. The argon flow at 1.15bar prevented leakage of oxygen into the cell. The effectiveness of oxygen exclusion was attested by the absence of significant oxidation of dithionite solution as monitored at $312 \mathrm{~nm}$ during an observation for over 2 hours. Before each experiment, the electrode was calibrated by injecting into the cuvette various volumes of buffer saturated with [NO] = $1 \%$ with a gas-tight Hamilton syringe. In this calibration, buffer saturated with $1 \mathrm{~atm}$ of $99 \%$ argon + $1 \% \mathrm{NO}$ has an effective $[\mathrm{NO}]=20 \mu \mathrm{M}$. This value derives from the reported solubility of pure NO in water at room temperature of $2 \mathrm{mM}$. The cuvette allowed simultaneous monitoring of NO and optical absorption with a 1600 Shimadzu UV/VIS spectrophotometer (Champs sur Marne, France). All experiments were carried out at room temperature. The experiments with iNOS were performed under a flow of argon and oxygen-saturated buffer was added to the solution. (The concentration of oxygen dissolved in $\mathrm{O}_{2}$-saturated buffer amounted to $1 \mathrm{mM}$ ).

Head space measurements of NO using chemiluminescence: Each protein sample $(10 \mu \mathrm{M})$ in an anaerobic solution containing $10 \mu \mathrm{M}$ nitrite, $20 \mu \mathrm{M} \mathrm{Ca}^{2+}$ / calmodulin, $1 \mathrm{mM} \mathrm{BH}_{4}$ and arginine, was measured with or without the addition of $100 \mu \mathrm{M}$ NADPH. In some experiments, nitrite was replaced by nitrate. The samples incubated in a sealed vial total volume $2.3 \mathrm{~mL}$ for $15 \mathrm{~min}$ at $25^{\circ} \mathrm{C}$. At that point $1.0 \mathrm{ml}$ of head space was removed as $1.0 \mathrm{ml}$ Ar was injected into vial. The head space sample was injected into the NOA.

Determination of nitrite concentration using the Griess method: anaerobic solutions of eNOS $(3 \mu \mathrm{M})$ were mixed with $1 \mathrm{mM}$ arginine, $40 \mu \mathrm{M} \mathrm{BH}_{4}, 15 \mu \mathrm{M}$ calmodulin and nitrite $(25,50 \mu \mathrm{M})$ in gastight vials. At $\mathrm{t}=0,50 \mu \mathrm{M}$ NADPH was added to the solutions and an aliquot was immediately removed for the Griess assay with a gas-tight syringe. A second aliquot was removed at $\mathrm{t}=20$ minutes. The aliquots were mixed in water with $20 \mu \mathrm{l}$ of a solution of $0.5 \mathrm{~g}$ sulfanilamide in $80 \mathrm{ml}$ and $20 \mu \mathrm{l}$ of a solution of $0.1 \% \mathrm{~N}$-Naphylethylenediamine (Griess reagent), the spectrum of the violet adduct was recorded after 5 minutes equilibration $\left(\lambda_{\max }=545 \mathrm{~nm}, \varepsilon=4.6 \times 10^{4} \mathrm{M}^{-1} \mathrm{~cm}^{-1}\right)$. Each determination of nitrite was done triplicate. Calibration was performed using known nitrite concentrations in the range of 10 to $100 \mu \mathrm{M}$ nitrite.

The kinetics of NADPH consumption and heme reduction were followed at $340 \mathrm{~nm}(\varepsilon=6200$ $\mathrm{M}^{-1} \mathrm{~cm}^{-1}$ ) and 396nm respectively; the experiments were performed in a quartz cuvette sealed with an air-tight septum (sup. Figure 3), which prevented loss of NO with the argon flow that could modify the kinetics. Absence of oxygen leaks in this cuvette was confirmed by the lack of dithionite decay monitored at $312 \mathrm{~nm}$. 
Cell cultures: Human dermal microvascular endothelial cells (HDMEC) were purchased from Science Cell Laboratories (Carlsbad, CA). These cells were cultivated to confluence in $75 \mathrm{~cm}^{2}$ flasks at $37^{\circ} \mathrm{C}$ under a controlled atmosphere containing $5 \% \mathrm{CO}_{2}$ and $20 \% \mathrm{O}_{2}$. The endothelial cell growth medium (ScienceCell) contained 5\% fetal calf serum, $1 \%$ of endothelial cell growth supplement, 10 $\mathrm{IU} / \mathrm{ml}$ penicillin and $100 \mu \mathrm{g} / \mathrm{l}$ streptomycin. The medium contains $500 \mu \mathrm{M} \mathrm{L}$-arginine so that depletion of this substrate is avoided even at high levels of NOS activity. At confluence, the bottom area of 75 $\mathrm{cm}^{2}$ was covered by a cellular monolayer. After aerobic culture of these cells for 24 hours, the medium was removed and the cells lifted by trypsinization. The cells $\left(\sim 2.5 \pm 0.5 \times 10^{6}\right)$ were suspended either in the old media $(7.0 \mathrm{ml})$ or new media $(7.0 \mathrm{ml})$ and $0.5 \mathrm{ml}$ of the cell suspension was added to $2.0 \mathrm{ml}$ septa topped screw cap glass vials (Supelco, Bellafonta, PA). The loosely capped vials were placed in the incubator for $1 \mathrm{~h}$ to allow the cells to adhere to the glass. The vials were placed in a $37^{\circ} \mathrm{C}$ water bath and either left loosely capped (normoxic) or tightly sealed and exposed via syringe needles (27.5 G, Becton-Dickinson, Franklin Lakes, NJ) through the septa to $60 \mathrm{ml} / \mathrm{min}$ of either a mixture of 2ppm $\mathrm{O}_{2}$ plus argon (hypoxic) or argon alone (anoxic) for $10 \mathrm{~min}$. At this point the needles were withdrawn, as a further precaution against leaks; the septa were sealed with tape. After different incubation times, $10 \mu \mathrm{l}$ of the cell medium was removed with an air-tight Hamilton syringe for injection into the chemiluminescent NO analyzer, (GE Analytical-Sievers Boulder, $\mathrm{CO}$ ) for the detection of nitrite + NO present in the medium with NaI in acetic acid. The NOS inhibitor L-N-MethylArginine (L-NMA, 500 $\mu \mathrm{M})$, nNOS specific inhibitor 3-Bromo-7-Nitro-indazole $(10 \mu \mathrm{M})$ or the xanthine oxydase inhibitor oxypurinol $(100 \mu \mathrm{M})$ were added at $\mathrm{t}=0$ or incubated for $15 \mathrm{mn}$ prior NOx detection. The detection limit was $500 \mathrm{fmol}$. Each experiment was performed in duplicate; NOx values reported are the average \pm S.D. of 3 repeat injections.

Time-resolved spectroscopy was performed with a $30 \mathrm{~Hz}$ pump-probe laser set-up described previously [31]. $50 \mu \mathrm{M}$ of protein (eNOSoxy or eNOS or nNOS) was equilibrated with $2.5 \mathrm{mM}$ arginine, $200 \mu \mathrm{M} \mathrm{BH}$ at various nitrite concentrations in a 1 -mm optical path quartz cuvette. The protein was reduced with dithionite; then, $\mathrm{NO}$ at a concentration of $0.1 \%$ in argon was introduced in the gas phase of the cuvette and equilibrated for $30 \mathrm{mn}$. Photodissociation of the NO ligand from nitrosylated heme was achieved by an excitation pulse at $565 \mathrm{~nm}$ with a pulse width of $30 \mathrm{fs}$. The transient spectrum detected after a variable delay was probed with a white light continuum pulse. The wavelength calibration of the CCD camera was checked by using a thin-bands filter. 25 optical spectra were accumulated at three time scales after the excitation pulse: 50 ps, 500 ps and 3 ns. Carbon monoxide ligands on ferrous myoglobin were used as reference of flat kinetics in the time scales of 500 ps to 3 ns [32].

\section{Results}

\section{A) Differences in NO release from nNOS and eNOS under anoxia}

(i) Effect of nitrite concentration on the nitrite reductase activity of eNOS

In anaerobic $50 \mathrm{mM}$ Tris buffer containing $\mathrm{BH}_{4}$, arginine, NADPH and $15 \mu \mathrm{M}$ nitrite at $\mathrm{pH}=$ 7.6, the NO-specific electrode showed a rapid increase in free NO produced by eNOS that reached $\approx$ $1 \mu \mathrm{M}$ after a few minutes (Figure $1 \mathrm{~A}$ ). The $15 \mu \mathrm{M}$ nitrite concentration was chosen close to that found in tissues [3,5]. After $1 \mathrm{hr}$, the $\mathrm{pH}$ of the solution remained unchanged at 7.6, showing that no acidification occurred. NO could not be detected if either eNOS or nitrite was omitted from the anoxic solutions containing NADPH. We confirmed that the release of free NO was concomitant with a consumption of nitrite by analyzing aliquots with Griess reagent. These aliquots were taken just after addition of NADPH ( $\mathrm{t}=0)$ or 20 minutes later. The quantity of consumed nitrite is the difference between these numbers and carries a large error margin. The nitrite consumption by eNOS linearly increased with increasing $\left[\mathrm{NO}_{2}^{-}\right]$and reached saturation (Figure 2). The amount of NO released followed a similar behavior, with an initial linear increase from $10 \mu \mathrm{M}$ to $50 \mu \mathrm{M} \mathrm{NO}_{2}^{-}$. In this $\left[\mathrm{NO}_{2}{ }^{-}\right]$ range, NADPH consumption rate also increased linearly and reached a maximum above $50-100 \mu \mathrm{M}$ $\mathrm{NO}_{2}^{-}$. Estimations of the stoichiometry of the reaction indicate that the anoxic nitrite reduction of eNOS required a $\sim 2$ fold excess of [nitrite] over [NO], while consuming of 1.0-1.5 nitrite per NADPH.

The release of free NO from eNOS-mediated nitrite reduction was also observed using an NOA analyzer in anaerobic solutions containing $10 \mu \mathrm{M}$ nitrite (Table 1). Moreover, we tested whether eNOS may reduce nitrate to nitrite, then to NO, like xanthine oxidase or the P450 reductase-P450 couple [13, 
17]. Substitution of nitrite by nitrate $(10 \mu \mathrm{M})$ resulted in the absence of NO within experimental error detected by chemiluminescence (Table 1).

\section{Effect of cofactors}

eNOS cannot utilize arginine under anoxic conditions (i.e. below the $\mathrm{O}_{2}-\mathrm{K}_{\mathrm{M}}$ of eNOS: $4-10 \mu \mathrm{M}$ ) [33]. Here this was confirmed by the fact that heme remained reduced in the presence of L-Arg $(\lambda=$ $409 \mathrm{~nm}$, sup. Fig. 1A). In contrast, in the presence both arginine and $500 \mu \mathrm{M}$ nitrite, the Soret band peaking around $415 \mathrm{~nm}$ showed a partial reduction of eNOS heme; the weak shoulder at $\sim 437 \mathrm{~nm}$ was indicative of the ferrous-NO complex formation (25\% nitrosylation). Concomitant with these spectral changes, $1.5 \pm 0.3 \mu \mathrm{M}$ NO was detected electrochemically (sup. Fig.1A-black line, Table 1 ). In the presence of nitrite alone, all of the eNOS was converted to ferrous-NO (sup. Fig.1A-red line, Table 1). The presence of the $\mathrm{BH}_{4}$ cofactor and arginine insured the correct high-spin status and stability of eNOS hemes. The absence of $\mathrm{BH}_{4}$ somewhat reduced the amount of NO released by eNOS from nitrite (sup. Fig. 1C). In the absence of arginine, no significant release of NO was detected (sup. Fig. $1 \mathrm{~A} \& \mathrm{C}$ ), even though the optical spectra demonstrated extensive (over $80 \%$ ) heme nitrosylation of eNOSoxy in the presence of nitrite (sup. Fig.1A-red line). The likely explanation for this is that under anoxia, in the presence of nitrite, arginine is not the source of NO but that it aids in the efficient release of NO as previously demonstrated in geminate recombination studies [34-36]. Moreover, EPR measurements confirmed the presence characteristic hyperfine triplet signal of the ${ }^{15} \mathrm{NO}$-adducts when ${ }^{15} \mathrm{~N}$-labeled nitrite was used [26]. We could estimate from simulations of the experimental EPR spectra that any putative ${ }^{14} \mathrm{NO}$-adducts (arising from unlabeled arginine conversion) should not overcome the upper limit of $5 \%$ of the ${ }^{15} \mathrm{NO}$-adducts [26].

\section{(ii) Effect of nitrite concentration on nNOS nitrite reductase activity}

Figure $1 \mathrm{~A}$ showed that nNOS did not release NO at $15 \mu \mathrm{M}$ nitrite within experimental error. The anoxic experiments were repeated at $500 \mu \mathrm{M}$ nitrite to enhance NO formation. A gradual and modest increase in free NO produced by nNOS reached $0.32 \pm 0.12 \mu \mathrm{M}$ after 90 minutes. The Griess reagent showed that nNOS consumed similar values of ca $22 \pm 5 \mu \mathrm{M}$ in 20 minutes than those obtained by eNOS at high $(250-500 \mu \mathrm{M})$ nitrite concentrations (Figure 3). Estimations of the stoichiometry of the reaction indicate that the anoxic nitrite reduction of nNOS taking place at $\left[\mathrm{NO}_{2}^{-}\right]>150 \mu \mathrm{M}$ required a $\sim 2.5$ fold excess of [nitrite] over [NADPH] with minor NO release but extensive heme nitrosylation (see below). In the low nitrite range $\left[\mathrm{NO}_{2}^{-}\right]<50 \mu \mathrm{M}$, nNOS consumed of ca 2 NADPH per nitrite but the electrode failed to detect $\mathrm{NO}$ and no sign of significant nitrosylation could be observed (Sup Fig. 2). We repeated the NO measurements using the more sensitive chemiluminescence assay (Table 1). Traces of NO, slightly above the background using anoxic solutions containing $10 \mu \mathrm{M}$ nitrite, could be detected by NOA

\section{Comparison the rates of reduction of eNOS/ nNOS}

To quantify the differences between nNOS and eNOS, single wavelength kinetics tested whether the heme reduction rate differed between the two isoforms at low nitrite concentration (supplementary figure 3). The absorbance changes at $340 \mathrm{~nm}(\mathrm{NADPH})$ and at $396 \mathrm{~nm}$ (ferric heme) were fitted by $\tau_{1}$ $=0.024 \pm 0.008 \mathrm{~s}^{-1}$ with a relative intensity of $78 \pm 3 \%$ in eNOS as compared to $\tau_{1}=0.015 \pm 0.005 \mathrm{~s}^{-1}$ with a relative amplitude $18 \pm 2 \%$. Surprisingly, the rate of heme reduction was faster in eNOS than in nNOS at low nitrite concentrations whereas the opposite holds true in the absence of nitrite [33]. The NADPH consumption of the two isoforms became similar at high nitrite concentration.

\section{(iii) Heme nitrosylation; Negative Feedback of NO/ Nitrite}

Figure 2 showed a plateau in the nitrite and NADPH consumption at [nitrite] $\geq 100 \mu \mathrm{M}$. We hypothesized that NO release could slow down as the reaction proceeds because of a negative feedback of NO on eNOS nitrite reductase activity under anoxia. This negative feedback would occur because of a steric hindrance of the nitrite ions binding to eNOS heme or heme pocket and limiting NO release from the protein. This hypothesis was tested by measuring the rate of NO geminate rebinding to the reduced heme of eNOSoxy in the presence of increasing nitrite concentrations. The extent of NO geminate rebinding allows estimating the probability of NO escape from the protein; the rate of NO dissociation from the ferrous nitrosyl complex, koff, depends on the rate of geminate 
rebinding [34-36]. The data have been analyzed according to three exponentials and a constant. As seen in Figure 4, nitrite enhances the weight $A_{1}$ of the fast component of NO rebinding in the picoseconds, from 0.05 in the absence of nitrite to $(0.63 \pm 0.04)$ at saturating nitrite / nNOS levels. The lifetime associated with A1, $\tau_{1}=(20 \pm 4)$ ps corresponded to recombination in the near vicinity of the heme iron (2-5 $\AA$ ). Simultaneously, the weight of the longer components and the level of asymptote decreases, while all time constants did not vary within experimental error, $\tau_{2}=(120 \pm 30) \mathrm{ps}$ and $\tau_{3}=$ $(1680 \pm 100)$ ps. The large increase of the weight $A_{1}$ is consistent with a steric effect of nitrite, preventing NO escape from the immediate heme vicinity. These experiments supported the possibility of a negative feedback of excess nitrite on the nitrite reductase activity of eNOS. The rebinding rate of NO to the ferrous heme of eNOS was also shown to reach saturation with excess NO as that shown in figure 4 in the presence of excess nitrite [34].

Very little NO escaped geminate recombination in nNOS WT (Figure 4), as expected from the reported feedback regulation of NO on nNOS catalysis and the above effect of added NO on NADPH consumption [33]. Moreover, the geminate recombination during $\tau_{1}=40 \pm 5 \mathrm{ps}$ was insensitive to [Nitrite] (2mM) concentration, in contrast with the marked enhancement of the ps decay of eNOS ( Sup Figure 4). A small effect of nitrite on the NO rebinding could be detected in the ns component, suggesting nitrite binding at distances $\geq 7-10 \AA$, with exceeding low NO escape probability from the heme. These data qualitatively explain the presence of the ferrous-NO complex formed by nNOS at $500 \mu \mathrm{M}$ nitrite monitored by absorption spectroscopy (suppl. Fig. 2). Heme nitrosylation, calculated from the ratio of the optical densities at $442 \mathrm{~nm}$ and independently obtained by curve fitting, reached $55-57 \%$ and $25 \%$ in nNOS and eNOS, respectively. The position of the $\alpha$ band, sensitive to nitrosylation, also attested at a low nitrosylation of eNOS as compared to nNOS (Suppl. Figure $1 \& 2$ ). Thus, the dominant fraction of NO formed by nNOS at $500 \mu \mathrm{M}$ nitrite was retained as a nitrosyl ligand of the heme together with small quantities of free NO (Figure 1B). This implied that NADPH consumption should be reduced by added NO, since nNOS heme was blocked in a ferrous nitrosyl form at high [nitrite]. Indeed, NADPH consumption during 20 minutes dropped from $10 \mu \mathrm{M}$ to 5.5 $\mu \mathrm{M}$ with the addition of $1 \mu \mathrm{M}$ NO to nNOS solutions in the presence of saturating nitrite concentrations. In contrast, the presence of added NO to eNOS marginally modified the NADPH consumption within experimental error (data not shown).

\section{B) iNOS does not consume nitrite under anoxia; effect of oxygen concentration}

The experiments were repeated with the inducible isoform, iNOS, using both $500 \mu \mathrm{M}$ and $15 \mu \mathrm{M}$ nitrite. The amount of free NO released by iNOS remained negligible, and nitrosylation of heme was unobservable by optical spectra both at 15 and $500 \mu \mathrm{M}$ nitrite (Figure 5 \& Suppl. Figure 2). The nitrite consumption also remained below our detection limit of ca $0.4 \mu \mathrm{M}$. The iNOS enzyme used was indeed active since its aerobic catalysis from arginine in the absence of nitrite yielded the release of $2.2 \pm 0.2 \mu \mathrm{M}$ NO. The normoxic yields of NO formed by iNOS are high, requiring $\mathrm{O}_{2}$ levels above the apparent $\mathrm{Km}$, ranging between $125 \mu \mathrm{M}$ (measured) and $25 \mu \mathrm{M}$ (calculated) [25, 33]. Since iNOS is unable to reduce nitrite under anoxia (Figure 5), no release of NO below the $\mathrm{K}_{\mathrm{M}}$ by iNOS was expected. We thus tested the effect of oxygen concentration on the NO released by iNOS using the nitrite concentration of $15 \mu \mathrm{M}$ in the presence of arginine. Thus, $\mathrm{O}_{2}$ was quickly utilized by the enzyme to produce NO, resulting in a sharp increase in the NO level that subsequently returned to baseline. Below $50 \mu \mathrm{M}$ oxygen, the amount of NO released remained very low. The NO released by iNOS followed a saturation curve consistent with an apparent $K_{M}$ value of about $60 \mu \mathrm{M}$ oxygen, in agreement with the reported values [25, 33].

\section{C) Functional properties of the isoforms and their subdomains.}

To investigate the role of the heme in nitrite reduction, we performed two sets of experiments. In the first one, we compare the NO release from the oxygenase domain of nNOS and eNOS, referred to as nNOSoxy and eNOSoxy respectively and of myoglobin (Mb), used as a "prototype hemoprotein". We also tested the isolated reductase domains of eNOS and nNOS referred ad eNOSred and nNOSred. In the third set, we investigated the effect of heme blockers and NOS inhibitors (substrate analogs) on the anoxic nitrite reduction by full length eNOS. 
(i) Comparison of nNOSoxy, eNOSoxy and Mb: For the experiments with the hemodomains nNOSoxy and eNOSoxy, reduction was induced by dithionite instead of NADPH. Dithionite consumes $\mathrm{OH}^{-}$when donating electrons; the $50 \mathrm{mM}$ Tris buffer was adequate to avoid acidification in our experiments and the electrode failed to detect traces of NO in the absence of protein (Table 1). The concentration of free NO released from eNOSoxy was ca three fold higher than from nNOSoxy, in qualitative agreement with the data obtained with WT eNOS and nNOS and the lower probability of NO escape from nNOS than from eNOS (Figure $4 \&$ Table 1). Myoglobin also reduced nitrite with a similar yield as nNOSoxy. When initial rates are compared, the differences between eNOSoxy and nNOSoxy are much smaller (Table 1). These data emphasize (a) the heme requirement in nitrite reduction to NO by the constitutive NOS as well as myoglobin (b) the strong modulation of the nitrite reductase activity of the wt enzymes by the presence of the reductase domain, although these domains by themselves had no intrinsic activity (see below).

(ii) Comparison of eNOSred, nNOSred to eNOS and nNOS at 10 $\mu \mathrm{M}$ nitrite

To test whether the reductase domains could participate in the nitrite reduction, isolated nNOS and eNOS reductase domains (nNOSred \& eNOSred respectively) were reduced by anaerobic NADPH solutions containing arginine with and without $10 \mu \mathrm{M}$ nitrite. Flavin reduction could be monitored by the decrease of the oxidized flavins band at $455 \mathrm{~nm}$ and the appearance of the broad blue (ca $600 \mathrm{~nm}$ ) semi-quinone radical. We tested the nitrite reductase activity by chemiluminescence measurements at low nitrite concentration $(10 \mu \mathrm{M})$. Table $1 \mathrm{C}$ shows that the isolated reductase domains of eNOS and nNOS referred ad eNOSred and nNOSred had no nitrite reductase activity in contrast with the WT enzymes; as expected, eNOS reduced efficiently nitrite into free NO, in agreement with the electrode data (figure 2). Nitrite slightly increased the rate of NADPH consumption by eNOSred and nNOSred (data not shown). These data suggest that nitrite may bind to the reductase of eNOS and nNOS although the isolated domains were unable to recycle nitrite into NO under anoxia.

(iii) Effect of NOS and unspecific inhibitors on NO formation and release from eNOS.

Table 1 also tested the role of NOS inhibitors on the anoxic nitrite reductase pathway. NLA or LNMA binding decreased the extent and the rate of nitrosylation of eNOSoxy as compared to that observed in the presence of arginine. Using NLA (2 mM) instead of arginine yielded a threefold decrease in the extent of NO formation by eNOS but inhibited eNOSoxy less (Table 1). The presence of $8 \mathrm{mM}$ SEITU significantly slowed the rate of NO release from eNOS but decreased the yield of free NO by only 15-20\%. Its bulkier analog IPITU [37] was a much more efficient inhibitor of eNOSmediated nitrite reduction. The non-specific heme-blocker imidazole $(5 \mathrm{mM})$ decreased the extent and rate of $\mathrm{NO}$ formation in the presence of arginine. In contrast, cyanide $(1 \mathrm{mM})$ completely blocked the NO release from eNOSoxy. Taken together, these data demonstrated that the heme plays an important role in nitrite reduction. The yield of NO release was also down-regulated by additional parameters including feed-back interactions, exemplified by the difference in NO yield between nNOS and nNOSoxy, as well as steric effects in the distal heme side.

\section{D) Hypoxic and anoxic NO formation from HDMEC cells}

HDMEC were first tested for NOS isozyme expression by western immunobloting which revealed that the cells contained eNOS but no detectable iNOS (data not shown).

The HDMEC were then exposed to the various oxygen regimes under ambient nitrite or subsequent to a 10 min exposure (during gas conditioning period) of the cells to $10 \mu \mathrm{M}$ nitrite. The ambient [nitrite] in old media was estimated to be $\sim 0.5 \mu \mathrm{M}$ (calculated from Fig. $6 \mathrm{t}=0$ circle symbols corresponding to cells incubated in old media: $\sim 5 \mathrm{pmol}$ in $10 \mu \mathrm{l}$ is injected into NOx analyzer, therefore $0.5 \mu \mathrm{M})$. Exposure of the cells containing $0.5 \mu \mathrm{M}$ nitrite to either room air or hypoxia (2ppm $\mathrm{O}_{2}$ ) or anoxia (argon) resulted no change in NOx production within experimental error (Fig. 6 circle symbols).

The concentration of extracellular nitrite estimated in the nitrite addition experiments was $\sim 9$ $\mu \mathrm{M}$ (Fig. $6 \mathrm{t}=0$ triangle symbols corresponding to cells incubated with $10 \mu \mathrm{M}$ nitrite). This means that $\sim 1 \mu \mathrm{M}$ nitrite was internalized during the 10 min incubation period. Therefore the changes in NOx detected in these series of experiments are thought to result from internalized nitrite being converted to 
NO and diffusing back into the medium (possibly, some nitrite may also bind / adsorb to the cells without internalization). Incubation of the cellular fraction of ca $1.8 \pm 0.5 \cdot 10^{5}$ HDMEC in aerobic medium yielded a time dependent increase in NOx with an estimated initial rate of $0.18 \mathrm{pmol} / \mathrm{min}$ (Figure 6- black triangles; inset- black bar). When normalized to the amount of NOx formed per minute and mg cells; this increase corresponded to a yield of $1.2 \pm 0.4 \mathrm{pmole} / \mathrm{min} \mathrm{x}$ mg, that compares well with a reported value of $0.8 \mathrm{pmole} / \mathrm{min} \mathrm{x} \mathrm{mg}$ as for the basal NO level in human [27, 38]. The exposure of the nitrite-added cells to hypoxic conditions $\left(2 \mathrm{ppm} \mathrm{O}_{2}\right.$ ) resulted in a 3.6-fold increase in the rate of NOx production (Figure 6- red triangles; inset- red bar). The largest NOx production rates 8.3-fold over basal were obtained under anoxia (argon) (Figure 6- green triangles; inset- green bar).

This anoxic yield could also be partly inhibited by preincubation with the non-specific NOS inhibitor L-NMA (data not shown). In contrast, incubation of the cells with oxypurinol or 3-Bromo-7nitroindazole did not modify the anoxic NO yield (data not shown). 3-Bromo-7-nitroindazole is a nNOS specific blocker [39], whereas oxypurinol specifically inhibits xanthine oxydase. The data rule out nNOS or xanthine oxidase as contributors to the anoxic production of $\mathrm{NO}$ in these cells. In addition, the viability of the endothelial cell cultures was not compromised by imposition of anoxia or hypoxia, since by Trypan-blue staining showed that cell death remained below $0.1 \%$ in all cases.

\section{Discussion}

Comparison of the nitrite reductase activity of the three NOS isoforms; Implication of the heme in nitrite reduction.

The anoxic nitrite reduction has important differences from the usual aerobic arginine pathway of NOS. First, the nitrite reduction by eNOS does not consume oxygen. Second, the kinetics and the amount of NO released depended on the nitrite concentration (Figures 1 and 2). Optical spectroscopy confirmed that both the flavins and the heme of eNOS must be reduced in order reduce nitrite to NO (suppl. Fig.1). Electron transfer from the reductase domain to the heme required calcium/ calmodulin binding. To show that the electron flow in eNOS is similar in both aerobic and anoxic pathways, $0.1 \mathrm{M}$ EDTA was added as a calcium chelator and this blocked NO formation from eNOS (data not shown). Our present studies have revealed a clear distinction between the nNOS, eNOS and iNOS isoforms: only the endothelial isoform was capable releasing a significant amount of free NO at physiological nitrite concentrations (Figures $1-3,5$ ). In order to account for these very different NO yields exhibited by the various NOS isoforms, different assumptions were tested:

(1) Structural dynamics differences of the heme pockets, responsible for different nitrite binding

(2) Difference in NO release efficiency from the heme; feedback regulation

(3) Difference in heme reduction rates related to changes in redox potential upon nitrite binding

(1) Structural dynamic differences: If we assume that nitrite is reduced at the heme, direct coordination of nitrite to the heme iron is required. However, we could not find evidence of direct coordination of nitrite to the reduced heme iron by absorption spectroscopy (data not shown). Geminate recombination studies rather indicate nitrite binds in close vicinity to the heme of eNOS (Figure 4) whereas similar studies with nNOS suggested that nitrite binding was different in the neuronal isoform. This relies on nitrite affecting NO rebinding to eNOS in ps, consistent with very short distances ca 3-5 $\AA$ from the heme. In contrast NO rebinding to nNOS was mainly affected in the ns step by nitrite ions. Thus ns timescales corresponded to distances of NO diffusion of ca 7-10 A from the heme being perturbed by nitrite binding. Additionally, Figure 2 shows the requirement of ca two nitrites per NO formed. Altogether, this suggested the involvement of an additional site besides the heme to reduce nitrite into NO, just like in the heme-based bacterial nitrite reductases that possess two close-by sites to perform their catalysis [40]. Nitrite "docking" could be performed by a distal arginine residue close to the heme and to the edge of the arginine substrate such as R252 in eNOS [30]. If nitrite binds this additional site and NO binds the close-by heme iron, this hypothesis could explain why excess nitrite could block this site by steric effects and hinder NO release from eNOS [34-36]. This hypothesis is also consistent with the effect bulky inhibitors on NO release (Table 1). The nitrite reduction can be described as:

$\mathrm{NO}_{2}^{-}+2 \mathrm{H}^{+}+\left[\mathrm{e}^{-}\right] \rightarrow \mathrm{NO}+\mathrm{H}_{2} \mathrm{O}$

$\mathrm{Fe}(\mathrm{III})+\mathrm{NADPH} \rightarrow \mathrm{Fe}(\mathrm{II})+\mathrm{NADP}+$ 
with concomitant oxidation of the heme iron (or a close-by site) delivering the reducing equivalent [e $\mathrm{e}^{-}$ ]). The source of the proton remains yet unidentified, although $\mathrm{BH}_{4}$ could be a potential proton (and electron) donor [41].

Nevertheless, we cannot rule out nitrite binding to the ferric heme that would probably occur at $\left[\mathrm{NO}_{2}^{-}\right]$ $>150 \mu \mathrm{M}$, since nitrite is known to be a weak heme ligand. In these conditions, the results could be explained by different binding modes of nitrite to nNOS and eNOS. Indeed, Ford proposed that different nitrite binding modes to the heme may result in different product formations [42]. Accordingly, in eNOS coordination of the nitrite would occur via the oxygen atom, ultimately producing NO. In nNOS, nitrite may coordinate via its nitrogen atom, ultimately resulting of different products than NO, possibly RSNO via a (Fe(II)-NO+)-intermediate with (active) thiols or HNO and subsequent $\mathrm{N}_{2} \mathrm{O}$ at acidic $\mathrm{pH}$. Such a hypothesis would explain the nitrite consumption by nNOS but the negligible amount of NO released (Figure 3).

(2) Feedback regulation. The three isoforms differ in the process of NO release from the heme into the solution [34-36]. NO dissociates more readily from eNOS (in both ferrous and ferric form [34]). In contrast, very little NO dissociated from the ferrous-NO complex of nNOS (Figure 4B), consistent with the enhanced nitrosylation with increasing [nitrite] (Fig 1, suppl. Fig. 2): at 250-500 $\mu$ M nitrite, nNOS heme nitrosylation was predominant. The catalytic process of nNOS could be blocked after the first cycle, since no oxygen can oxidize it back to the free $\mathrm{Fe}(\mathrm{III})$ form via the futile cycle, and $\mathrm{Fe}(\mathrm{II})$ is blocked in a ferrous-nitrosyl complex [25]. Additionally, a smaller distal heme pocket of iNOS as compared to eNOS was previously suggested to account for the geminate recombination of NO to iNOS being independent on the NO concentration, in contrast to [NO] dependency found in eNOS [34-36]]. Such structural constraints probably apply to the larger nitrite ion as compared to NO and explain the lack of nitrite reductase activity of iNOS.

(3) Differences in heme reduction. The presence of nitrite significantly impeded NADPH consumption and heme reduction with respect to the reported rates of heme reduction: $0.1,(0.9-1.5)$ up to (3-4) $\mathrm{s}^{-1}$ for eNOS, iNOS and nNOS respectively without nitrite [25, 33]. Figure 3 demonstrated that NADPH at $340 \mathrm{~nm}$ as well the heme ferric state at $396 \mathrm{~nm}$ decayed faster in eNOS as compared to that in nNOS at low nitrite concentrations. The heme redox potential of the NOS isoforms, although similar in absence of nitrite [43-44], could be modified upon nitrite binding. This hypothesis would partly explain the smaller difference in NO yield between eNOSoxy and nNOSoxy ( 2.5 fold) as compared to that observed between the full-length enzymes ( 7.3 fold). Additionally, the regulation of the heme potential by substrate or substrate analogs binding $[43,44]$ that may affect the NO yield cannot be ruled out.

Implications for physiology: A number of enzymes are now known to catalyze nitrite reduction to NO under hypoxia: xanthine oxidase [9,13], cytochrome C oxidase [16], myoglobin [14], hemoglobin [4, 7-8, 15, 45], cytochrome P450 [17] as well as eNOS considered here (Tables $1 \& 2$ ). We note that these pathways for nitrite reduction are triggered at different local oxygen thresholds and likely will not act synchronized. We propose that eNOS have a physiological significance for acute hypoxia at physiological $\mathrm{pH}$. This proposition is based on:

(i) The cellular data presented here demonstrated the relevance of the nitrite reduction pathway not only under anoxia but also acute hypoxia at $10 \mu \mathrm{M}$ nitrite, close to tissue levels [3,5]. The rates of NO produced by the HDMEC cells were enhanced by $\sim 8.3$-fold and $\sim 3.6$-fold over the basal level under anoxia and hypoxia respectively (Figure 6, inset). These data are consistent with a previous study using anoxic cultured endothelial BEND3 cells that contained only eNOS [27, 28, 46]. In contrast with BEND3 cells, the microvascular cells used in this work were sensitive to extracellular nitrite, suggesting potential different paths of nitrite internalization in these cell types.

The hypoxic NO formed by HDMEC cells was inhibited by L-NMA, but not the 3-Bromo-7nitroindazole, a nNOS specific inhibitor (data not shown). eNOS was also the only active NOS protein under low (physiological) nitrite and oxygen concentrations in vitro (Table 1). Moreover, purified eNOS retained its ability to reduce nitrite over three repeated argon / oxygen cycles (data not shown). Both in vitro and cellular data confirm that the only NOS isoform with a hypoxic nitrite reductase activity is eNOS. The magnitude of the hypoxic NO release, reaching 3.6 times higher levels than 
basal normoxic ones, provides an appropriate response to ischemia. Moreover, this response is sustained for ca 10-15 minutes. As such, the eNOS-mediated reaction would help to counter the negative effects of acute and episodic ischemia near the endothelium precisely when vasodilatation by NO is most needed. It is likely that this would be a short-time "emergency" effect, in particular at $\mathrm{pH} \geq 7.6$ where xanthine oxidase nitrite reductase activity decreases [9, 13, 52].

(ii) A plethora of animal studies showed a protective role of eNOS in the early stages of ischemia [18-19, 21-23, 47-51] whereas other isoforms were often reported cytotoxic [22, 23]. These publications suggest that eNOS acts as a protective agent against acute ischemic damage to various organs as an immediate but short-term response [21]. Indeed, early infusion of nitrite was found to be protective in brain ischemia-reperfusion injury [53]. In contrast, enzymatic activity of nNOS is often found to contribute to ischemic damage to the brain [19]. Taken together, these animal studies show that eNOS and nNOS respond oppositely to acute hypoxia. In acute hypoxia, iNOS is inactive, but becomes activated upon reperfusion. Our study stressed the rationale for the differences between the NOS isoforms. eNOS is unique in that it releases NO under all oxygen levels from normoxia to complete anoxia at physiological $\mu \mathrm{M}$ nitrite concentrations.

\section{References}

[1] Rassaf, T., Kleinbongard, P., Kelm, M. (2006) The circulating NO pool in humans. Kidney Blood Press. Res. 28, 341-348.

[2] Rodriguez, J., Maloney, R.E., Rassaf, T., Bryan, N.S., Feelisch, M. (2003) Chemical nature of nitric oxide storage forms in rat vascular tissue. Proc. Natl. Acad. Sci. USA 100, 336-41.

[3] Gladwin, M.T., Schechter, A.N., Kim-Shapiro, D.B., Patel, R.P., Hogg, N., Shiva, S., Cannon, R.O., Kelm, M., Wink, D.A., Espey, M.G., Oldfield, E.H., Pluta, R.M., Freeman, B.A., Lancaster, J.R., Feelish, M., Lundberg, J.O. (2005) Nature Chem. Biol. 1, 309-14.

[4] Gladwin, M.T., Shelhamer, J.H., Schechter, A.N. (2000) Role of circulating nitrite and Snitrosohemoglobin in the regulation of the regional blood flow in humans. Proc. Natl. Acad. Sci. U.S.A. 97, $11482-7$.

[5] Lundberg, J.O., Weitzberg, E. (2005) NO generation from nitrite and its role in vascular control. Artheroscler. Thromb. Vasc. Biol. 25, 363-6.

[6] Bryan, N., Fernandez, B. Bauer, S. (2005) Nitrite is a signaling molecule and regulator of gene expression in mammalian tissues. Nature Chem.Biol. 1, 290 - 297.

[7] Duranski, M.R., Greer, J.J., Dejam, A., Jaganmohan, S., Hogg, N., Langston, W., Patel, R.P., Yet, S.F., Wang, X., Kevil, C.G., Gladwin, M.T., Lefer, D.J.. (2005) Cytoprotective effects of nitrite during in vivo ischemia-reperfusion of the heart and liver. J. Clin. Invest. 115, 1232-40.

[8] Crawford, J.H., Isabell, T.S., Huang, Z., Shixa, S., Chackp, B.K., Schechter, A.N., DarleyUsmar, V.M., Kerby, J.D., Lang, J.D., Kraus, D., Ho, C., Gladwin, M.T., Patel, R.P. (2006) Hypoxia; red blood cells and nitrite regulate NO-dependent hypoxic vasodilation. Blood 107, 566-74.

[9] Li, H., Samouilov, A., Liu, X., Zweier, J. (2003) Characterization of the Magnitude and Kinetics of Xanthine Oxidase-catalyzed Nitrate Reduction: Evaluation of its role in nitrite and nitric oxide generation in anoxic tissues. Biochemistry 42, $1150-1159$.

[10] Samouilov, A., Kuppusamy, P., Zweier, J. (1998) Evaluation of the magnitude and rate of nitric oxide production from nitrite in biological systems. Arch. Biochem. Biophys. 357, 1-7.

[11] Frerat F., Sonveaux P., Rath G., Smoos A., Meqor A., Charlier N., Jordan B.F., Saliez J., Noel A., Dessy C., Gallez B., Feron O (2008) The acidic tumor microenvironment promotes the reconversion of nitrite into NO: toward a new and safe radiosensitizing strategy Clin. Cancer Res. 14, 2768-74.

[12] Lundberg, J.O. (2006) Nitric oxide metabolites and cardiovascular disease. J. Am. Coll. Cardiol 47, 580-1

[13] Millar, T.M., Stevens, C.R., Benjamin, N., Eisenthal, R., Harrison, R., Blake, D.R. (1998) Xanthine oxidoreductase catalyses the reduction of nitrates and nitrite to nitric oxide under hypoxic conditions. FEBS Lett. 427, 225-8.

[14] Rassaf T., Flögel U., Drexhage C., Hendgen-Cotta U., Kelm M., Schrader J., (2007) Nitrite reductase function of deoxymyoglobin: oxygen sensor and regulator of cardiac energetics and function. J. Circ Res. 100,1749-54. 
[15] Cosby, K., Partovi, K.S, Crawford, J.H., Patel, R.P., Reiter, C.D., Martyr, S., Yang, B.K., Waclawiw, M.A., Zalos, G., Xu, X., Huang, K.T., Shields, H., Kim-Shapiro, D.B., Schechter, A.N., Cannon, R.O., Gladwin, M.T. (2003) Nitrite reduction to nitric oxide by deoxyhemoglobin vasodilates the human circulation. Nature Med. 9, 1498-1505.

[16] Castello, P., Woo, DK., Ball, K., Wojcik, J., Liu, L., and Poyton, R. (2006) Mitochondrial cytochrome oxidase produces nitric oxide under hypoxic conditions: Implications for oxygen sensing and hypoxic signaling in eukaryotes. Cell Metabolism 3, 277 - 287.

[17] Li, H., Liu, X., Cui, H., Chen, YR., Cardounel, AJ., Zweier, JL. (2006) Characterization of the mechanism of cytochrome P450 reductase-cytochrome P450-mediated nitric oxide and nitrosothiol generation from organic nitrates J. Biol. Chem. 281, 12546-54.

[18] Wei, G., Dawson, V.L., Zweier, J.L. (1999) Roles of neuronal and endothelial NOS in NO generation in the brain following cerebral ischemia Biochem. Biophys. Acta 1411, 23-34; 1999.

[19] Moro, M., Cardenas, A., Hurtado, J., Leza, C. and Lizasoain I, (2004) Role of nitric oxide after brain ischaemia. Cell Calcium.36, 265-75.

[20] Bolli R. (2001) Cardioprotective function of inducible NO synthase and role of nitric oxide in myocardial ischemia and preconditioning: an overview of a decade of research. J. Mol. Cell. Cardiol. 33, 1897-918.

[21] Endres, M., Laufs, U., Lia, J.K., Moskowitz, M.A. (2004) Targeting eNOS for stroke protection. Trends Neurosci. 27, 283-9.

[22] Liu V.W. \& Huang P.L; (2008) Cardiovascular roles of nitric oxide: a review of insights from nitric oxide synthase gene disrupted mice Cardiovasc. Res. 77, 19-29.

[23] Altay, T., Gonzales, E.R., Park, T.S., Gidday J.M. (2004) Cerebrovascular inflammation after brief episodic hypoxia: modulation by neuronal and endothelial NOS. J. Appl. Physiol. 96, 1223-1230.

[24] Atochin D.N., Wang A., Liu V.W., Critchlow J.D., Dantas A.P., Looft-Wilson R., Murata T., Salomone S., Shin H.K., Ayata C., Moskowitz M.A., Michel T., Sessa W.C., Huang P.L. (2007) The phosphorylation state of eNOS modulates vascular reactivity and outcome of cerebral ischemia in vivo. J Clin Invest. 117,1961-7.

[25] Stuehr, D.J., Santolini, J., Wang, Z.Q., Wei, C.C., Adak, S. (2004) Update on mechanism and catalytic regulation in the NO -synthases J. Biol. Chem. 279, 36167-36170.

[26] Gautier, C., van Faassen, E., Mikula, I., Martasek, P., Slama-Schwok, A. (2006) Endothelial nitric oxide synthase reduces nitrite anions to NO under hypoxia. Biochem. Biophys. Res. Comm. 34, 816-821.

[27] Vanin, A., Bevers, L.M., Slama-Schwok, A., van Faassen, E. (2007) Nitric oxide synthase reduces nitrite to NO under anoxia. Cell. Mol. Life Sci. 64, 96-103.

[28] Bevers, L., Braam, B., Post, J.A., van Zonneveld, A.J., Rabelink, T., Koomans, H., Verhaar, M., Joles, J. (2006) Tetrahydrobiopterin but not L-arginine decreases NO synthase uncoupling in cells expressing high levels of endothelial NO synthase. Hypertension 47, 87 - 94.

[29] Martasek, P., Liu, Q., Liu, J., Roman, L.J., Gross, S.S., Sessa, W., Masters, B.S.S. (1996) Characterization of bovine endothelial nitric oxide synthase expressed in E. coli. Biochem. Biophys. Res. Commun. 219, 359-365.

[30] Raman, C.S., Li, H., Martasek, P., Kral, V., Masters, B.S.S., Poulos, T.L. (1998) Crystal structure of constitutive endothelial nitric oxide synthase: a paradigm for pterin function involving a novel metal center. Cell 95, 939-950.

[31] Martin, J.-L., Vos MH. (1992) Femtosecond biology. Annu. Rev. Biophys. Biomol. Struct. 21, $199-22$.

[32] Petrich, J., Poyat, C., Martin J.-L. (1988) Photophysics and reactivity of heme proteins: a femtosecond absorption study of hemoglobin; myoglobin; and protoheme. Biochemistry 27, 40494060.

[33] Santolini, J., Meade, A.L., Stuehr D.J. (2001) Differences in Three Kinetic Parameters Underpin the Unique Catalytic Profiles of Nitric-oxide Synthases I; II; and III. J. Biol. Chem. 276, 48887-98.

[34] Slama-Schwok, A., Negrerie, M., Berka, V., Lambry, J.C., Tsai, A.L., Vos, M.H., Martin J.L..(2002) Nitric oxide (NO) traffic in endothelial NO synthase. Evidence for a new NO binding site dependent on tetrahydrobiopterin? J Biol Chem. 277, 7581-6. 
[35] Gautier, C., Negrerie, M., Wang, Z.Q., Lambry, J.C., Stuehr, D.J., Collin, F., Martin, J.L., Slama-Schwok A. Dynamic Regulation of the Inducible Nitric-oxide Synthase by NO: COMPARISON WITH THE ENDOTHELIAL ISOFORM (2004) J Biol Chem. 279, 4358-65.

[36] Gautier, C., Mikula, I., Nioche, P., Maratasek, P., Raman, C.S., Slama-Schwok A (2006) Dynamics of NO rebinding to the heme domain of NO-synthase-like proteins from bacterial pathogens. Nitric Oxide 15, 312-27.

[37] Li, H., Raman, C.S., Martasek P., Kral, V, Masters, B.S., Poulos T.L. (2000) Mapping the active site polarity in structures of endothelial nitric oxide synthase heme domain complexed with iosthioureas. J. Inorg. Chem. 81, 133-9.

[38] Kelm M. (1999) Nitric oxide metabolism and breakdown. Biochem. Biophys.Acta 1411,273289.

[39] Raman, C.S., Li, H., Martasek, P., Southan, G., Masters, B.S., and Poulos, TL. (2001). Crystal structure of nitric oxide synthase bound to Nitro-indazole reveals a novel inactivation mechanism Biochemistry 40, 13448-55.

[40] Wasser, I., de Vries, S., Loccoz, P., Schroder, I., Karlin, K. (2002) Nitric oxide in biological denitrificationL $\mathrm{Fe} / \mathrm{Cu}$ metalloenzyme and metal complex Nox redox chemistry. Chem. Rev. 102, 1201-34.

[41] Gorren A.C.F., Sorlei M., Anderssson K., Marchal S., Lange R., Mayer B. (2005) Tetrahydrobiopterin as combined electron/proton donor in nitric oxide biosynthesis. Methods in Enzymology 396, 456-66.

[42] Kurtikyan T.S., Hovhannisyan M.E., Hakobyan J.C., Patterson A, Irestskii A., Ford P.C. (2007) J.Am. Chem. Soc. 129, 3576-85.

[43] Sennequier N., Stuehr D.J (1996) Analysis of substrate-induced electronic; catalytic and structural changes in inducible NO synthase. Biochemistry 35, 5883-92.

[44] Gao, Y.T., Weinberg, J.B., Montgomery, H.J., Newmann, E., Guillemette, J.G., Ghosh, D.K., Roman, L.J., Martasek, P., Salerno, J.C. (2004) Thermodynamics of oxidation-reduction reactions in mammalian nitric oxide synthase isoforms. J. Bol. Chem. 279, 18759-66.

[45] Nagababu E., Ramasamy S., and Rifkind J.M. (2007) Intermediates Detected by Visible Spectroscopy during the Reaction of Nitrite with Deoxyhemoglobin: The Effect of Nitrite Concentration and Diphosphoglycerate Biochemistry 46, 11650-59.

[46] van Faassen, E., Vanin, A, Slama-Schwok., A. (2007) Chapitre 14: Nitrite as endothelial NO donor under anoxia; In: van Faassen, E.; Vanin, A; Eds Radicals for Life: The various forms of Nitric Oxide. Elsevier Amsterdam p 291 - 312.

[47] Yu, J., Demuinck, E.D., Zhuang, Z., Drinane, M., Kauser, K., Rubanyi, G.M., Qian, H.S., Murata, T., Escalante, B., Sessa, W.C. (2005) Endothelial nitric oxide synthase is critical for ischemic remodeling, mural cell recruitment, and blood flow reserve. Proc. Natl. Acad. Sci. U S A. 102, 109991004.

[48] Murohara, T., Asahara, T., Silver, M., Bauter, C., Masuda, H., Kalka, C., Kearny, M., Chen, D., Symes, J.F., Fishman, M.C., Huang, P.L., Isner J.M. (1998) Nitric oxide synthase modulates angiogenesis in response to tissue ischemia. J. Clin. Invest. 101, 2567-78.

[49] Sakai, K., Hirooka, Y., Shigematsu, H., Kishi, T., Ito, K., Shimokawa, H., Takeshita, A., Sunagawa, K. (2005) Overexpression of eNOS in brain stem reduces enhanced sympathetic drive in mice with myocardial infarction. Am. J. Phys. Heart Circ. Physiol. 289, H2 159-66.

[50] Kaminski, A., Pohl, C.B., Sponholz, C., Ma, N., Stamm, C., Vollmar, B., Steinhoff G. (2004) Up-regulation of endothelial nitric oxide synthase inhibits pulmonary leukocyte migration following lung ischemia-reperfusion in mice. Am. J. Pathol. 164 , 2241-9.

[51] Beleslin-Cokic, B.B., Cokic, V.P., Yu, X., Weksler, B.B., Schechter, A.N., Noguchi, C.T. (2004) Erythropoietin and hypoxia stimulate erythropoietin receptor and nitric oxide production by endothelial cells. Blood 104, 2073-80.

[52] Webb AJ, Milsom AB, Rathod KS, Chu WL, Qureshi S, Lovell MJ, Lecomte FM, Perrett D, Raimondo C, Khoshbin E, Ahmed Z, Uppal R, Benjamin N, Hobbs AJ, Ahluwalia A.(2008) Mechanisms underlying erythrocyte and endothelial nitrite reduction to nitric oxide in hypoxia: role for xanthine oxidoreductase and endothelial nitric oxide synthase. Circ Res. 103(9), 957-64. 
[53] Jung, K.H., Chu, K., Ko, S.Y., Lee, S.T., Sinn, D.I., Park, D.K., Kim, J.M., Song, E.C., Kim, M., Roh, J.K. (2006) Early intravenous infusion of sodium nitrite protects brain against in vivo ischemiareperfusion injury. Stroke 37, 2744-50.

ACKNOWLEDGMENT: Financial support by EGIDE (ECONET n ${ }^{\circ} 10275 N$ to AS) is gratefully acknowledged. PM is supported by grants from MSMT of Czech Republic 1M 6837805002 and 0021620806 . BM’s contribution to this study was supported by a NSERC Discovery Grant.

\section{Figure Legends}

Figure 1: eNOS and nNOS markedly differ in their anoxic NO release from nitrite: A: Electrode traces measured at $15 \mu \mathrm{M}$ nitrite, nNOS did not release NO (blue) whereas a gradual increase of NO was induced by eNOS (red); B: NO electrode current (pA) generated at $500 \mu \mathrm{M}$ nitrite; a weak NO signal was slowly released from nNOS (blue), in contrast with the fast and large NO release mediated by eNOS (red). The control experiments did not show any NO produced at $15 \mu \mathrm{M}$ or at 500 $\mu \mathrm{M}$ nitrite in the absence of protein (black). NADPH had a starting concentration of $100 \mu \mathrm{M}$, [nNOS] $=7 \mu \mathrm{M}$ and $[\mathrm{eNOS}]=5 \mu \mathrm{M}$. The solutions contained Tris buffer ( $50 \mathrm{mM}, \mathrm{pH}=7.6), 150 \mathrm{mM} \mathrm{NaCl}, 5 \%$ glycerol, $1 \mathrm{mM}$ arginine, $40 \mu \mathrm{M} \mathrm{BH}_{4}, 10 \mu \mathrm{M}$ Calmodulin, $1 \mathrm{mM} \mathrm{Ca}^{2+}$ kept under constant argon flow. $1 \mu \mathrm{M}$ NO yielded a signal of $750 \mathrm{pA}$.

Figure 2: Anoxic nitrite reductase activity of eNOS as a function of the nitrite concentration [nitrite] $=\mathbf{1 0 - 5 0 0} \mu \mathrm{M}$. The rates of NADPH consumption (squares) and NO release (circles) are shown on the left scale in units of $\mu \mathrm{M}$ species per $\mu \mathrm{M}$ eNOS per minute; the $\mu \mathrm{M}$ amount of nitrite consumed in 20 minutes per $\mu \mathrm{M}$ protein (triangles) is shown on the right scale, $150 \mathrm{mM}$ $\mathrm{NaCl}, 50 \mathrm{mM}$ Tris buffer $\mathrm{pH}=7.6,1 \mathrm{mM}$ arginine, $40 \mu \mathrm{M} \mathrm{BH}_{4}, 10 \mu \mathrm{M}$ Calmodulin, $1 \mathrm{mM} \mathrm{Ca}^{2+} \mathrm{kept}$ under constant argon flow.

Figure 3: Anoxic activity of nNOS as a function of the nitrite concentration [nitrite] = 10$\mathbf{5 0 0 \mu M}$; same conditions as in Figure 2.

Figure 4: A-Nitrites enhance NO geminate rebinding to eNOSoxy reduced heme; NO is detached from the ferrous nitrosyl complex at $\mathrm{t}=0$ by the pump beam and the kinetics of its rebinding to the heme is followed by the probe beam as a function of time. The normalized decays of the ferrous heme resulting from NO rebinding to the heme are shown on the left, using [Nitrite] $=0$ : $\mathbf{\square}, 2.5 \mathrm{mM}$ : ○; $8.5 \mathrm{mM}$ : * and $0.1 \%$ NO. The zero ordinates correspond to the full recovery of the ferrous nitrosyl complex. The right inset shows the coefficients $\mathrm{A}_{1}-\mathrm{A}_{4}$ obtained from the fits of the data (shown as full lines on the experimental data on the left graph) as a function of the nitrite / eNOS ratio. B: Efficient NO release from eNOSoxy in contrast with NO being confined to the heme in nNOSoxy using $[\mathrm{NO}]=0.1 \%$ nNOSoxy (triangles), $\tau_{1}=(42 \pm 9) \mathrm{ps}\left(\mathrm{A}_{1}=0.29\right), \tau_{2}=(230 \pm 50) \mathrm{ps}\left(\mathrm{A}_{2}=0.48\right), \tau_{3}=(1.3 \pm$ $0.2)$ ns $\left(\mathrm{A}_{3}=0.17\right), \mathrm{A}_{4}=0.06$; eNOSoxy (squares): $\tau_{1}=(20 \pm 4) \mathrm{ps}\left(\mathrm{A}_{1}=0.05\right), \tau_{2}=(90 \pm 15) \mathrm{ps}\left(\mathrm{A}_{2}=0.30\right), \tau_{3}=$ $(1.7 \pm 0.2) \mathrm{ns}\left(\mathrm{A}_{3}=0.38\right), \mathrm{A}_{4}=0.26$.

Figure 5: Lack of free NO released by iNOS under argon in contrast with NO formation from iNOS in the presence of $15 \mu \mathrm{M}$ nitrite at large oxygen concentration. The right panel shows the electrode traces after consecutive additions of $50 \mu \mathrm{M}, 100 \mu \mathrm{M}$ and $25 \mu \mathrm{M}$ oxygen after the initial injection of NADPH under argon at $\mathrm{t}=0$ in a solution of iNOS containing $500 \mu \mathrm{M}$ nitrite. The left panel summarizes the NO level formed by iNOS in the presence of $15 \mu \mathrm{M}$ nitrite as function of the added oxygen concentration. The red line corresponds to the calculated saturation curve, with an apparent transition at $60 \pm 10 \mu \mathrm{M}$ oxygen at $15 \mu \mathrm{M}$ nitrite. The electrode response was $1000 \pm 90 \mathrm{pA}$ for $1 \mu \mathrm{M}$ NO in solution; same conditions as in Figure 1.

Figure 6: Enhanced NOx release by HDMEC cells under anoxia and hypoxia as compared to normoxia with $10 \mu M$ nitrite added; Left: HDMEC were exposed to room air (black symbols) or 2ppm O2 (red symbols) or argon (green symbols) in the presence of $10 \mu \mathrm{M}$ added nitrite (triangles) or ambient nitrite concentrations (circles). Little NOx changes were observed at ambient nitrite concentrations of ca $0.5 \mu \mathrm{M}$ (circles). Each experiment was performed in duplicate; NOx values reported in units of pmole are the average \pm S.D. of 2 repeat injections. Right Insert: initial rate of NOx formation in units of pmole $\mathrm{NOx} / \mathrm{min}$ in normoxia (ambient air), hypoxia (2ppm oxygen) and anoxia (argon). 
Table 1: Summary of the halftime and yields of NO release from the reduction of nitrite under anoxia

\begin{tabular}{|c|c|c|c|}
\hline $\begin{array}{l}\text { A) Oxygenase domain } \\
\text { High nitrite }\end{array}$ & $\begin{array}{c}\tau_{1 / 2}(\mathrm{NO}) \\
\min ^{1}\end{array}$ & $\begin{array}{c}{[\mathrm{N} 0] \pm 15 \%} \\
(\mu \mathrm{M})^{2}\end{array}$ & $\begin{array}{l}{[\mathrm{N} 0](\mu \mathrm{M} / \mu \mathrm{M}} \\
\text { protein } / \mathrm{min})^{3}\end{array}$ \\
\hline No enzyme & & 0 & +2 \\
\hline eNOSoxy $+\mathrm{BH}_{4}+$ Arginine & 2.5 & 1.5 & $0.17 \pm 0.03$ \\
\hline nNOSoxy $+\mathrm{BH}_{4}+$ Arginine & $\approx 0.5$ & 0.6 & $0.12 \pm 0.03^{4}$ \\
\hline $\mathrm{Mb}$ & $\approx 0.5$ & $0.4^{*}$ & $0.08 \pm 0.03$ \\
\hline $\begin{array}{l}\text { eNOSoxy+BH }{ }_{4}+\mathrm{NLA}(1 \\
\mathrm{mM})\end{array}$ & 23 & 1.2 & \\
\hline $\begin{array}{l}\text { eNOSoxy } \mathrm{BH}_{4}+\text { Arginine }+ \\
\text { Imidazol }(5 \mathrm{mM})\end{array}$ & 43 & 1.0 & \\
\hline $\begin{array}{l}\text { eNOSoxy }+\mathrm{BH}_{4}+\text { Arginine } \\
+\mathrm{CN}^{-}(1 \mathrm{mM})\end{array}$ & & 0 & \\
\hline $\begin{array}{l}\text { B) WT NOS } \\
\text { High nitrite }\end{array}$ & $\begin{array}{c}\tau_{1 / 2}(\mathrm{NO}) \\
\min ^{1}\end{array}$ & $\begin{array}{c}{[\mathrm{N} 0] \pm 15 \%} \\
(\mu \mathrm{M})^{2}\end{array}$ & $\begin{array}{l}{[\mathrm{N} 0](\mu \mathrm{M} / \mu \mathrm{M}} \\
\operatorname{protein} / \mathrm{min})^{3}\end{array}$ \\
\hline No enzyme & & 0 & \\
\hline eNOS $+\mathrm{BH}_{4}+$ Arginine & $\approx 0.3$ & 2.2 & $0.45 \pm 0.03^{4}$ \\
\hline $\begin{array}{l}\text { eNOS+ } \mathrm{BH}_{4}+\mathrm{NOHA}(1 \\
\mathrm{mM})\end{array}$ & $\approx 0.4$ & 2.0 & \\
\hline $\mathrm{eNOS}+\mathrm{BH}_{4}+\mathrm{NLA}(2 \mathrm{mM})$ & 0.9 & 0.7 & \\
\hline $\begin{array}{l}\text { eNOS+ } \mathrm{BH}_{4}+\mathrm{SEITU}(8 \\
\mathrm{mM})\end{array}$ & 3.0 & 1.7 & \\
\hline $\begin{array}{l}\text { eNOS+ } \mathrm{BH}_{4}+\mathrm{IPITU}(8 \\
\mathrm{mM})\end{array}$ & 10 & 0.5 & \\
\hline nNOS $+\mathrm{BH}_{4}+$ Arginine & 29 & 0.3 & $0.002 \pm 0.001$ \\
\hline $\begin{array}{l}\text { C) Reductase domain or } \\
\text { WT NOS, low nitrite }\end{array}$ & & [N0] (nmol) & $\begin{array}{l}{[\mathrm{N} 0](\mu \mathrm{M} / \mu \mathrm{M}} \\
\text { protein } / \mathrm{min})\end{array}$ \\
\hline eNOSred & 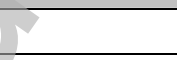 & 0 & 0 \\
\hline nNOSred & & 0 & 0 \\
\hline eNOS & & $3.1 \pm 0.6$ & $0.21 \pm 0.05$ \\
\hline nNOS & & $0.24 \pm 0.19$ & $0.016 \pm 0.013$ \\
\hline
\end{tabular}

A and B): Electrochemical detection of NO using A) [oxygenase domain] $=2-4 \mu \mathrm{M}, 1 \mathrm{mM}$ nitrite or B) fulllength [NOS] = 3-7 $\mu \mathrm{M}$ repleted with 5 molar excess of $\mathrm{Ca}^{2+} /$ calmodulin, $500 \mu \mathrm{M}$ nitrite under argon in $50 \mathrm{mM}$ Tris buffer at $\mathrm{pH}=7.5,150 \mathrm{mM} \mathrm{NaCl}$ after addition of $100 \mu \mathrm{M}$ reducing agent (dithionite in A and NADPH in B); in the myoglobin (Mb)* experiments, the nitrite concentration was [nitrite] $=1 \mathrm{mM}$

${ }^{1}$ : Time required reaching $50 \%$ of the maximal [NO] $\left(\tau_{1 / 2}(\mathrm{NO})\right)$ monitored by the electrode

2: Maximal value in \% of the electrode current after NADPH injection compared to "normal" conditions for which $1 \mathrm{mM}$ arginine and $12 \mu \mathrm{M} \mathrm{BH}_{4}$ was used in the presence of a five fold molar excess of calmodulin. The fourth column presents the maximal NO concentrations in $\mu \mathrm{M}$ determined after calibration of the electrode

${ }^{3}$ : Initial rate of NO formed in $\mu \mathrm{M}$ per $\mu \mathrm{M}$ protein per minute

${ }^{4}$ : the value is the lower limit of the rate, because NO release is too fast to be accurately determined (limited by the risetime of the electrode response)

C): Chemiluminescence measurements of NO formed at $10 \mu \mathrm{M}$ nitrite by $100 \mu \mathrm{l}$ of $10 \mu \mathrm{M}$ isolated reductase domains or B) WT NOS, $20 \mu \mathrm{M} \mathrm{Ca}^{2+}$ /calmodulin, $1 \mathrm{mM} \mathrm{BH4,} 1 \mathrm{mM}$ arginine under argon in $50 \mathrm{mM}$ Tris buffer at $\mathrm{pH}=7.5,15$ minutes after addition of 100 $\mu \mathrm{M}$ NADPH (see experimental). 


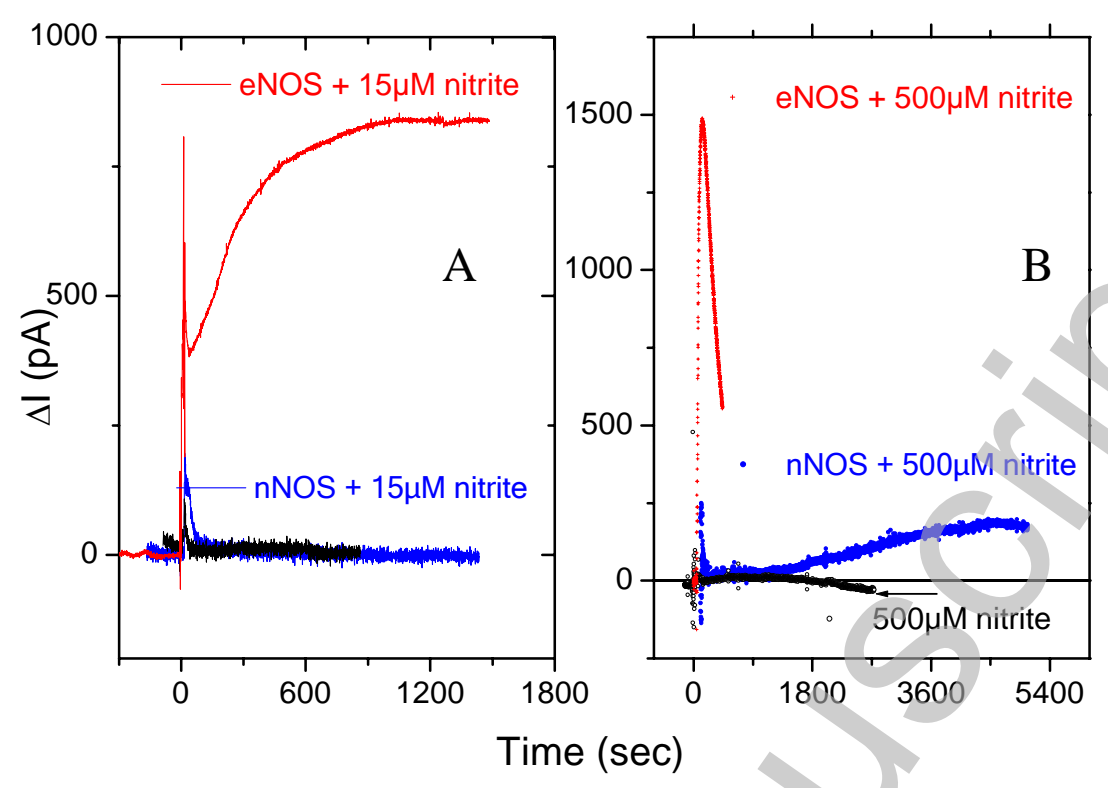

Figure 1 


\section{Figure 2}

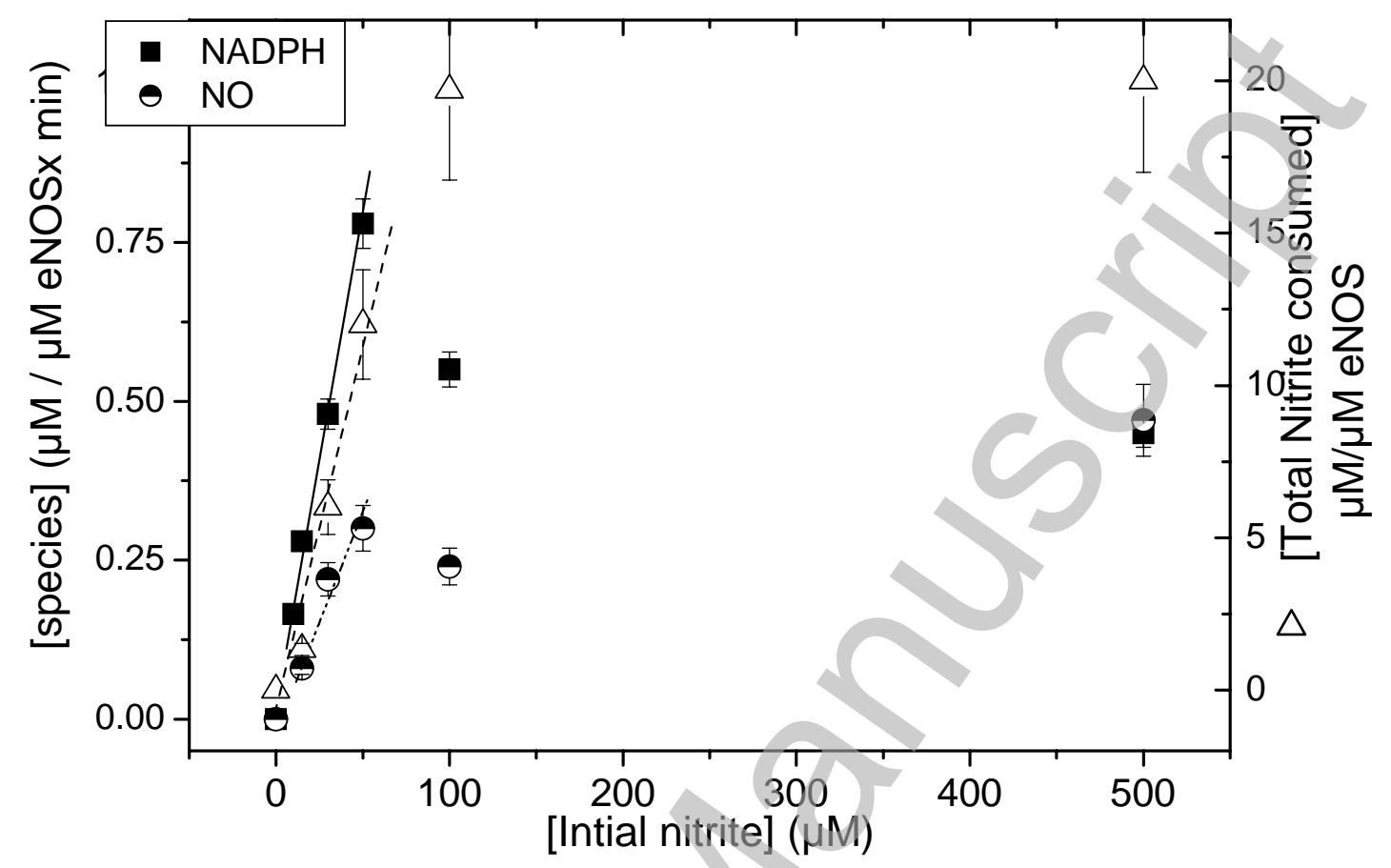




\section{Figure 3}

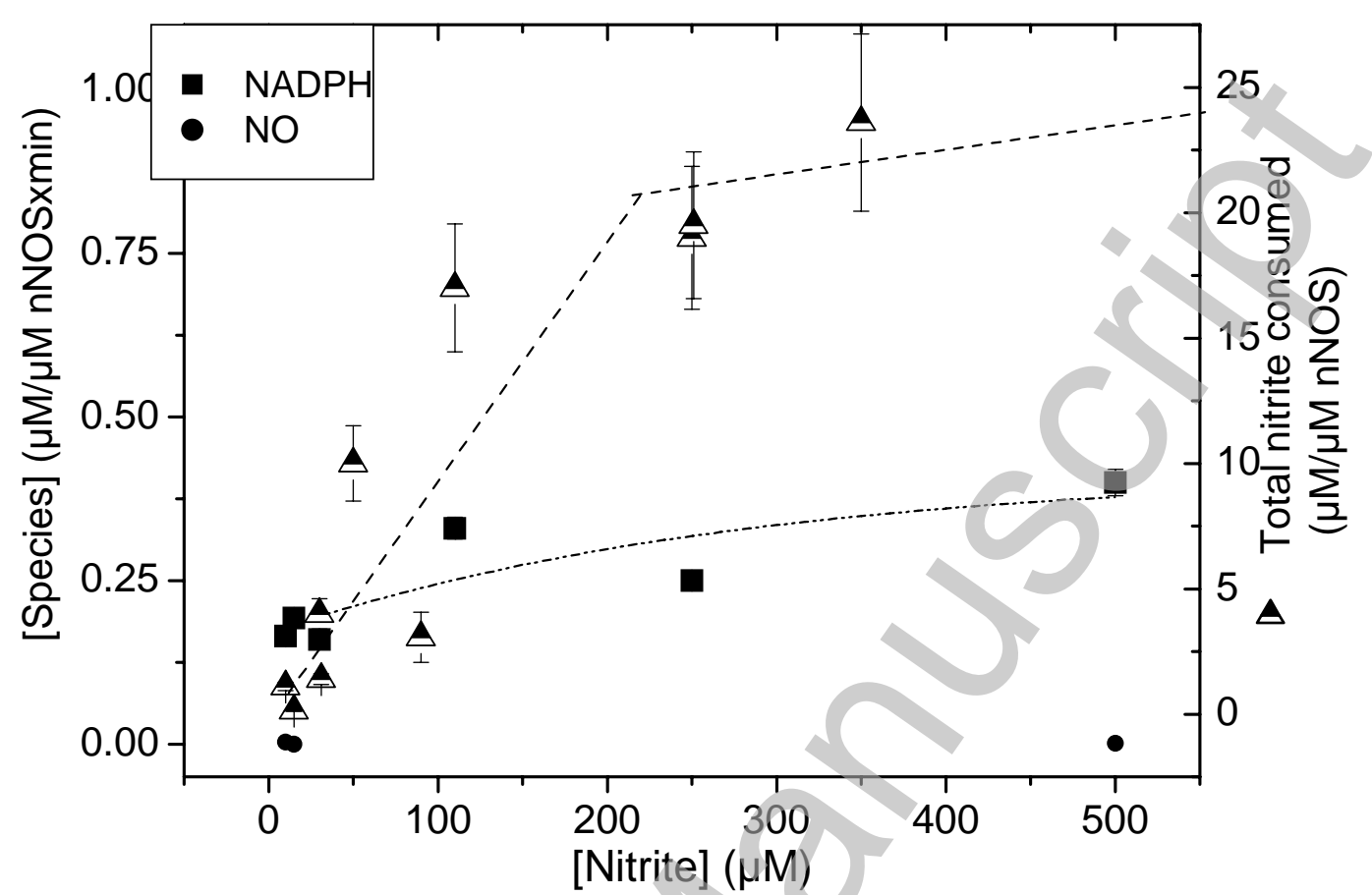



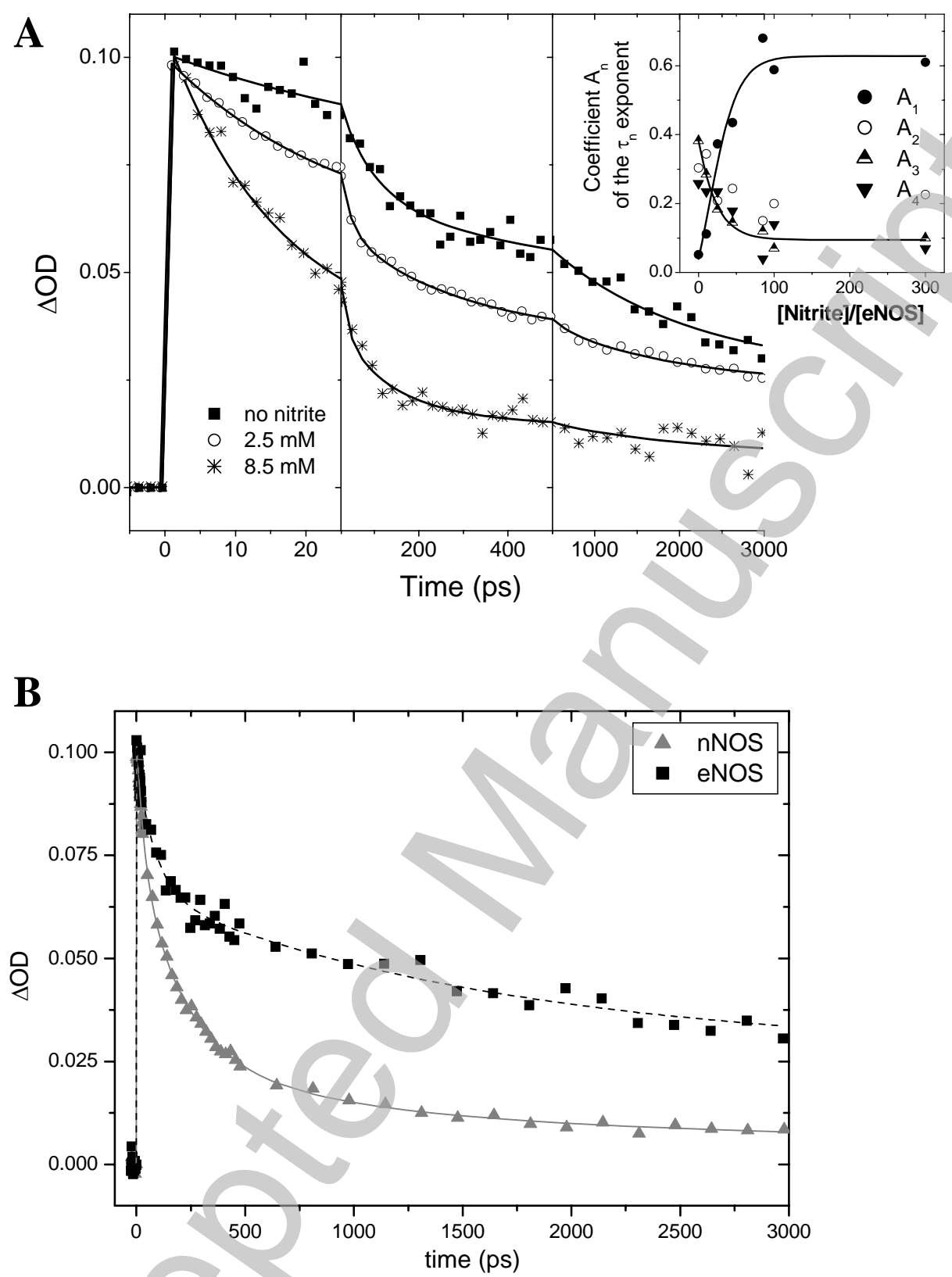

Figure 4

Licenced copy. Copying is not permitted, except with prior permission and as allowed by law. (C) 2008 The Authors Journal compilation (c) 2008 Portland Press Limited 


\section{Figure 5}

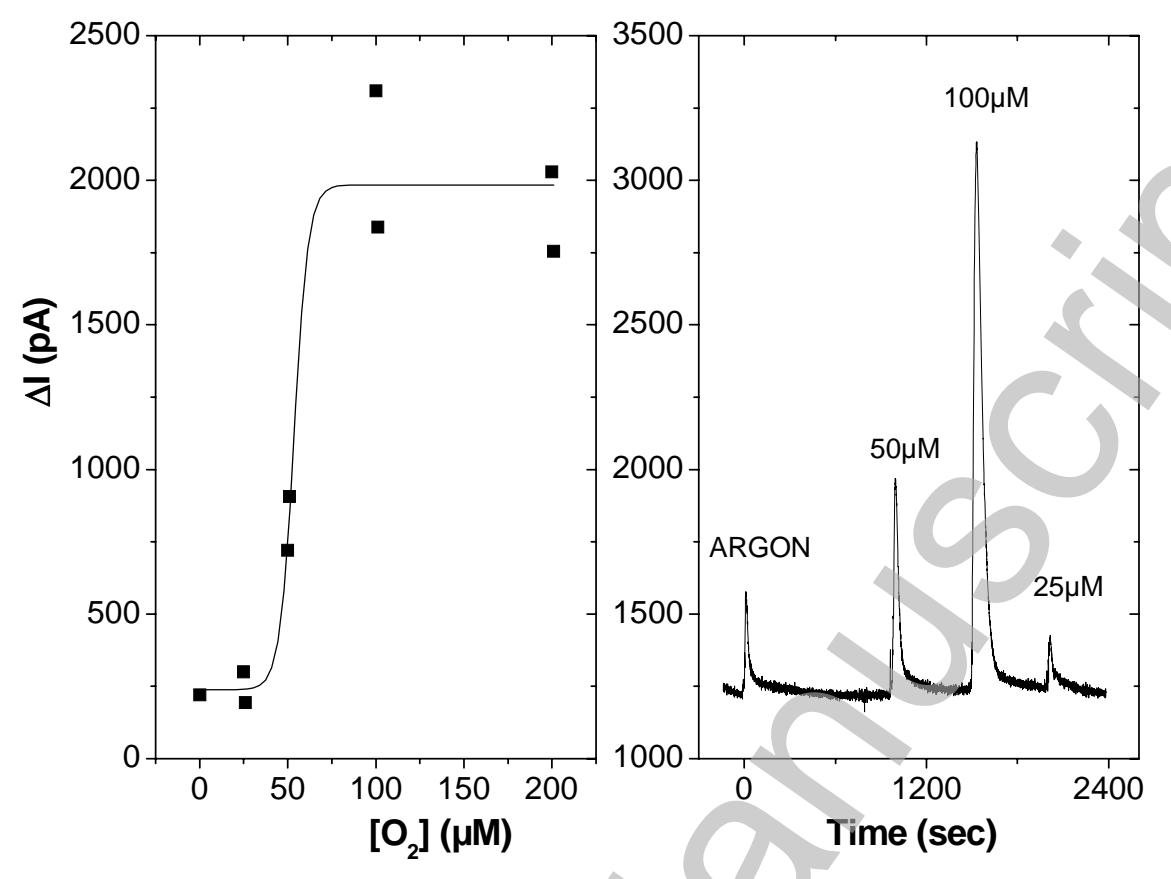



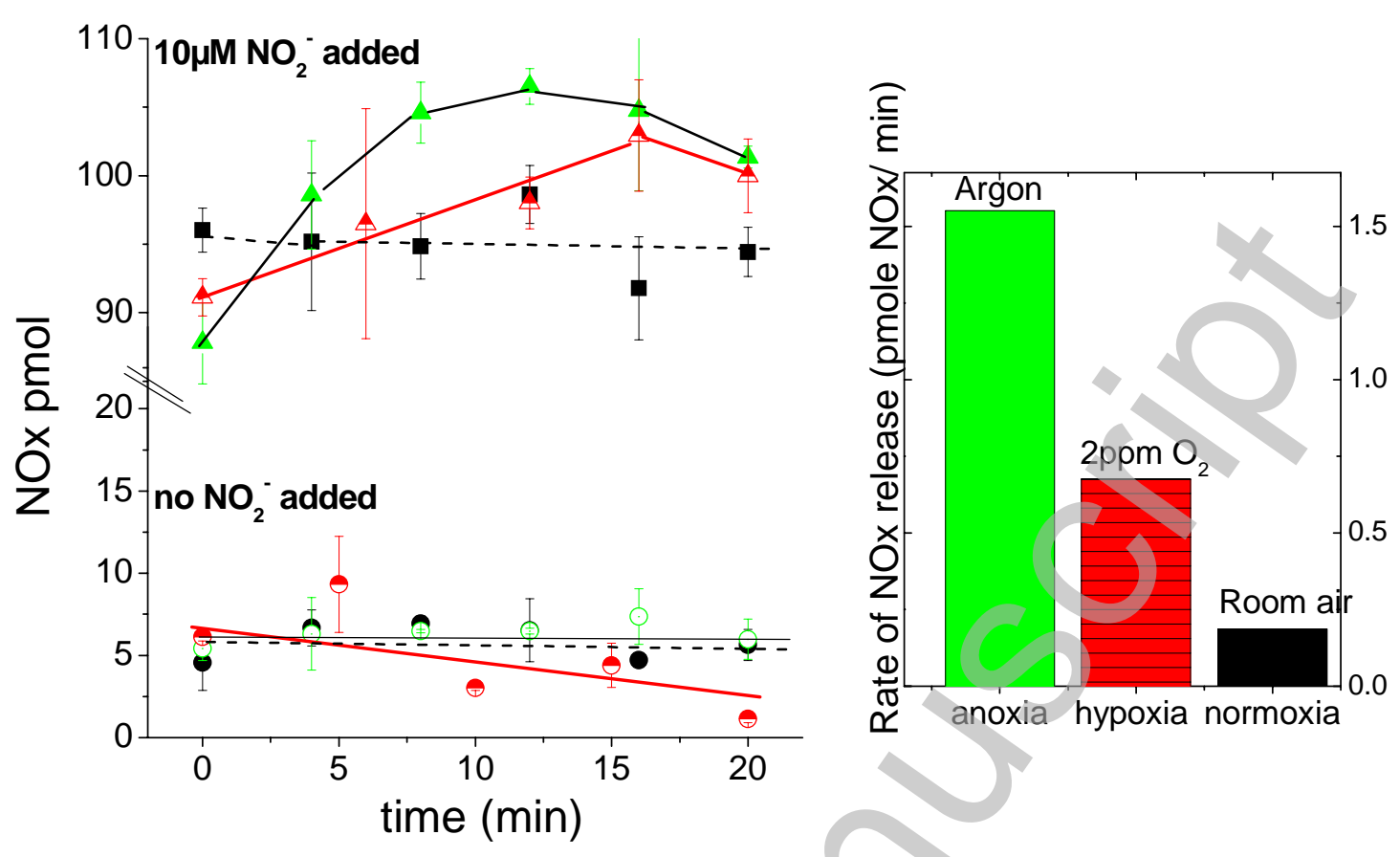

Figure 6 